\title{
Effect of nitrates on LOS pressure in achalasia: a potential therapeutic aid
}

\author{
M GELFOND, P ROZEN, S KEREN, AND T GILAT* \\ From the Department of Gastroenterology. Ichilov Hospital and Sackler Medical School, \\ Tel-Aviv University, Tel-Aviv, Isreal
}

SUMMARY The effect of a long-acting nitrate, isosorbide dinitrate (ID) $5 \mathrm{mg}$ sublingually, on the lower oesophageal sphincter was tested in 24 patients with achalasia. The drug caused a reduction in LOS pressure in all cases. The mean LOS pressure fell from $46 \cdot 3 \pm 2.7 \mathrm{mmHg}$ to $15 \cdot 3 \pm 1.8 \mathrm{mmHg}$ $(\mathbf{P}<0.01)$. The pressure began to drop after several minutes, reaching its lowest levels after 15 minutes. This measured manometric effect lasted for 60 minutes or more in 10 patients studied. The reported clinical effect lasted for two to three hours, permitting the ingestion of a meal. Twentythree patients were followed clinically for two to 19 months while receiving the drug three times daily before meals. Nineteen reported a marked to complete relief of dysphagia. Five of these patients had previous pneumatic dilatation, cardiomyotomy, or both, and had recurrence at time of study. Side-effects, mainly headache, were reported in eight patients. In six this was alleviated by substituting oral isosorbide dinitrate, $10 \mathrm{mg}$. Two patients became refractory to treatment after two to six months. The potential role of long-acting nitrates in the treatment of achalasia has yet to be established.

Present-day therapy for achalasia is symptomatic, aimed at reducing the lower oesophageal sphincter pressure (LOSP). Pneumatic dilatation and cardiomyotomy are both effective by causing mechanical damage to the sphincter. They carry a small but appreciable morbidity and even mortality. Because the dysphagia in achalasia is caused by a functional, not a mechanical, obstruction, it is logical to look for pharmacological means of reducing the raised LOSP.

Despite several trials involving anticholinergics and adrenergic blockers, ${ }^{1-7}$ there is at present no drug suitable for this purpose. Short-acting nitrates and nitrites were evaluated in the $1940 \mathrm{~s}$ and $1950 \mathrm{~s}^{8-11}$ and discarded because of side-effects and brief duration of action.

In the present study long-acting nitrates were evaluated manometrically and clinically and found to be of value in the treatment of the disease.

Methods

PATIENTS

Twenty-four patients with achalasia were studied.

*Address for correspondence and reprint requests: T Gilat, MD, Ichilov Hospital, Weizmann Street, Tel-Aviv, Israel.

Received for publication 18 November 1980
Each had typical symptoms for more than one year. Radiographic studies, oesophagogastroscopy, and an oesophageal motility test were performed in each case and were diagnostic of achalasia. Their clinical and manometric data are given in Table 1. Fifteen of the patients were females, nine males, and their ages ranged from 21 to 78 years. Eight had undergone previous therapy (pneumatic dilatation and/or cardiomyotomy) and were again symptomatic at the time of study.

All patients had dysphagia; 17 had regurgitation; nine had pulmonary symptoms; and 14 had a weight loss of over $5 \mathrm{~kg}$. Dilatation of the oesophagus was assessed radiologically and endoscopically. As radiographic studies were performed at various institutions without a standardised technique, the dilatation was graded arbitrarily as mild $(1+)$, moderate $(2+)$, or severe-'sigmoid' oesophagus $(3+)$. Six patients had no dilatation of the oesophagus.

On manometric study all but two patients had an LOSP of $30 \mathrm{mmHg}$ or more. None had complete relaxation of the sphincter during swallowing; 11 had incomplete relaxation; the others had no relaxation. The contractions in the body of the oesophagus were simultaneous in 22 patients (in five they were 
Table 1 Clinical and manometric data of study patients

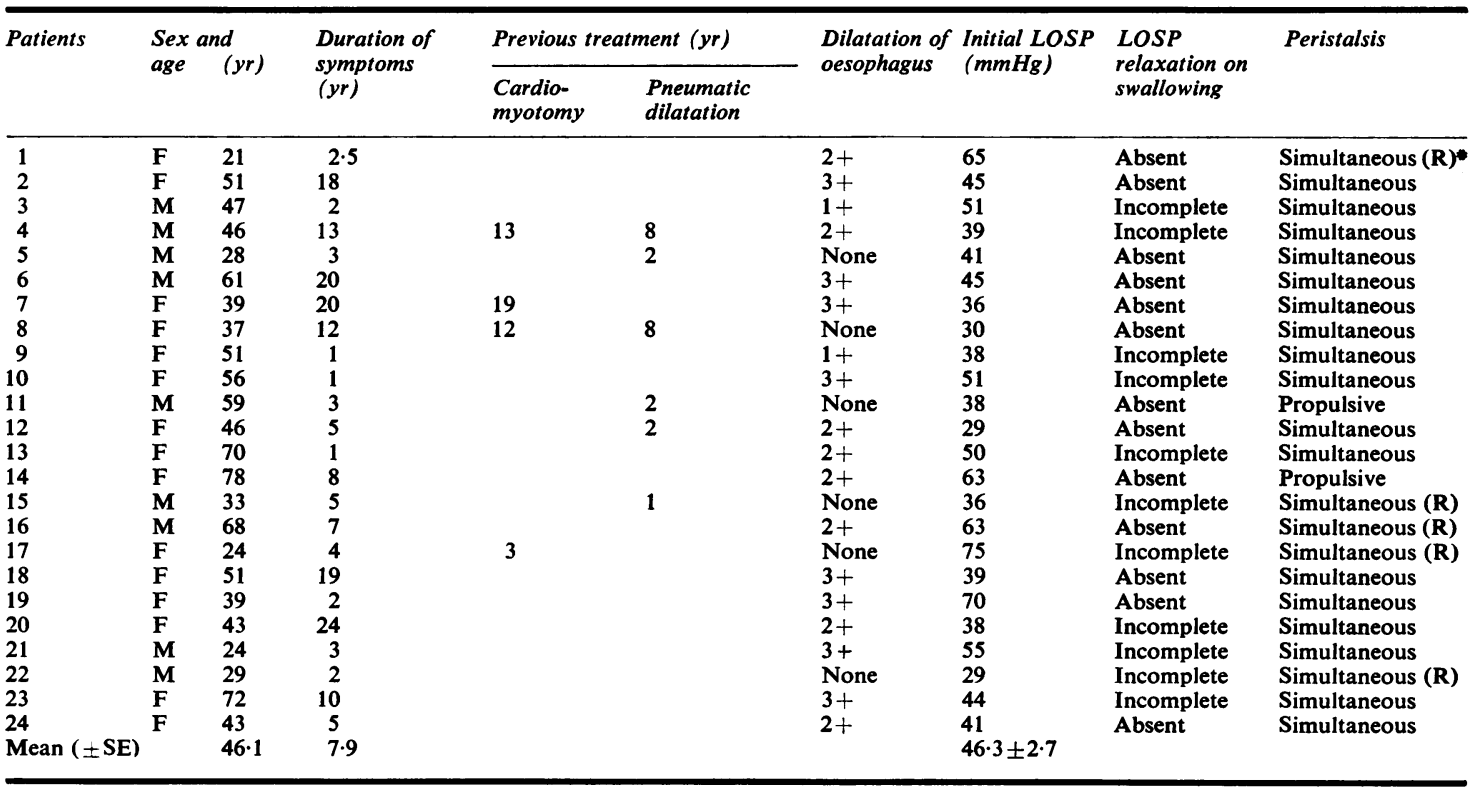

*R Repetive.

also repetitive) and propulsive in two. In nine the contractions, though simultaneous, were of a very low amplitude and almost absent.

\section{TECHNIQUES}

Oesophageal motility was recorded by polyvinyl catheters of $1.6 \mathrm{~mm}$ internal diameter with side orifices $5 \mathrm{~cm}$ apart arranged to form a single assembly. The catheters were perfused with water at $1.1 \mathrm{ml} / \mathrm{min}$ using a Harvard constant perfusion syringe pump. Pressure was measured by Statham model P23Dc transducers (Statham, POB 1178, Nato Rev., Puerto-Rico), and recorded on a Beckman RM Dynograph recorder type 700 (Beckman Instruments, 3900 N. River Road, Schiller Park, USA). The speed of recording was $2.5 \mathrm{~cm} / \mathrm{s}, 1 \mathrm{~cm} / \mathrm{s}$, and $1 \mathrm{~cm} / \mathrm{min}$. The motility tests were performed using the pull-through technique. ${ }^{12}$ LOS pressure was calculated from the midpoint of the curve during quiet respiratory excursions.

Oesophageal motility was studied in two stages. At first the motility of both sphincters and the body was recorded and evaluated. After the diagnosis was established the catheter was replaced in the LOS and the pressure was again recorded. The basal LOSP was thus a mean of at least two separate measurements. Isosorbide dinitrate (ID) $5 \mathrm{mg}$ was then given sublingually and the pressure continuously recorded for 15-90 minutes. During the recording period several pull-through manoeuvres were performed to ascertain the correct location in the LOS. In seven patients the pressure was thus recorded for over 60 minutes and in three patients for over 90 minutes. In five patients the LOS reaction to sublingual nitroglycerine $0.65 \mathrm{mg}$ was also evaluated in a separate study. The recordings were read and measured independently by two investigators, one of whom was unaware of the medication sequence.

At the end of each study the patients were given a sandwich to eat and were asked about dysphagia. Each patient was then given ID $5 \mathrm{mg}$ sublingual tablets to be taken three times a day 15 minutes before meals. They were then invited for follow-up at one week, one month, and then every two to three months. At each visit they were questioned about their dysphagia. The results were graded as good (no dysphagia), moderate (marked improvement with occasional dysphagia), and poor (no significant improvement.)

The statistical significance of differences was tested by Student's non-paired $t$ test. All patients gave their informed consent to the study, which was conducted in accordance with the principles of the Helsinki Declaration.

\section{Results}

EFFECT ON LOSP

Figures 1 and 2 demonstrate the decrease in LOSP after ID $5 \mathrm{mg}$ sublingually in two patients with achalasia. The recording was continued for 90 


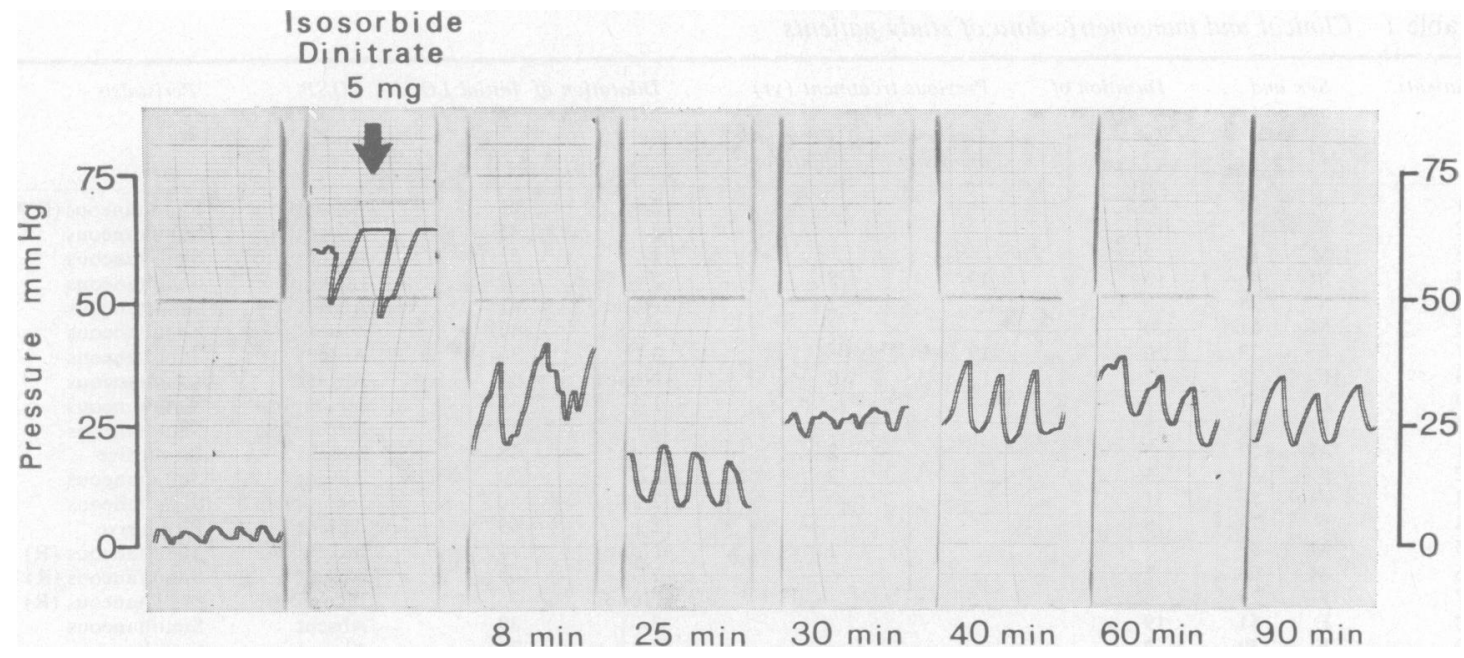

Fig. 1 Strips of the original recording of the LOSP of patient no. 1 showing LOSP before and eight, 25, 30, 40, 60, and 90 minutes after $5 \mathrm{mg}$ isosorbide dinitrate sublingually. Pressure fell from $65 \mathrm{mmHg}$ to $28 \mathrm{mmHg}$ and remained low for the 90 minutes of the recording. (At 25 minutes a pressure of $12.5 \mathrm{mmHg}$ was recorded, for a very brief period). The left hand strip shows the baseline intragastric pressure.

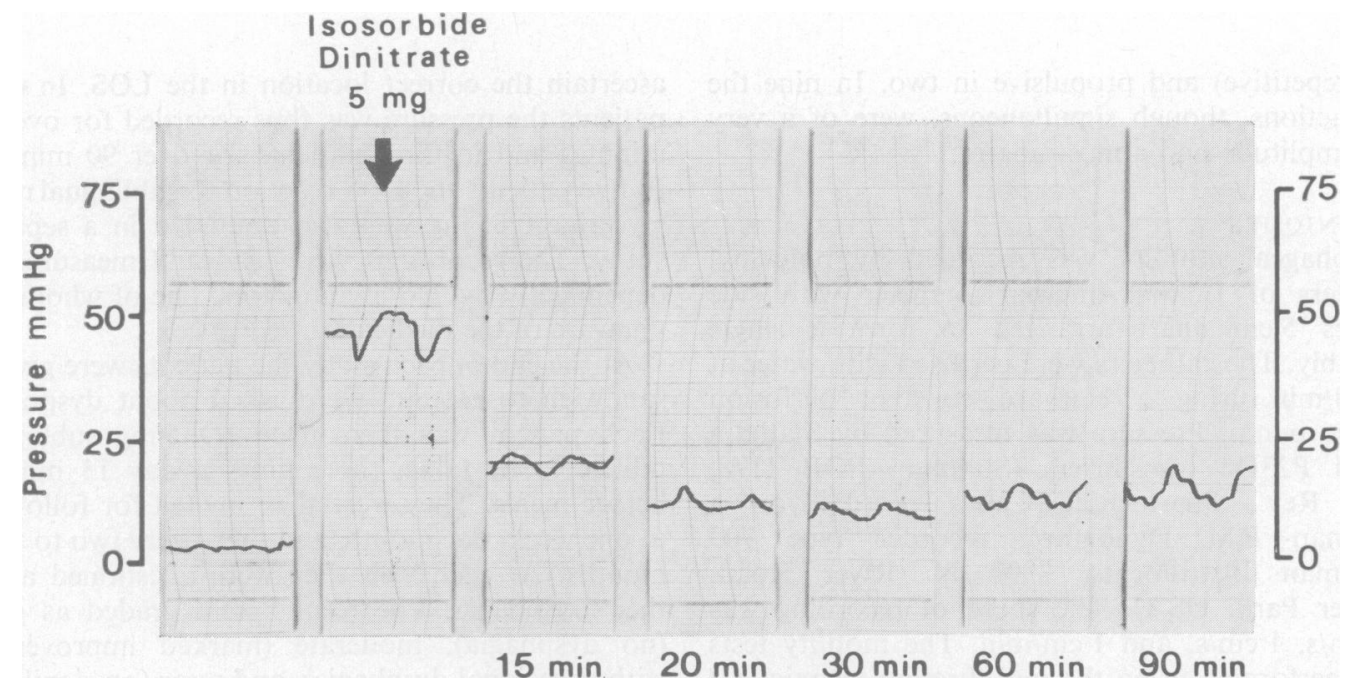

Fig. 2 Strips of the original recording of the LOSP of patient no. 3 showing LOSP before and 15,20,30,60, and 90 minutes after $5 \mathrm{mg}$ isosorbide dinitrate sublingually. Pressure fell from $51 \mathrm{mmHg}$ to $13 \mathrm{mmHg}$ and remained at this level for the 90 minutes of the recording. The left hand strip shows the baseline-intragastric pressure.

minutes in each case. LOSP fell from 65 to $28 \mathrm{mmHg}$ and from 51 to $13 \mathrm{mmHg}$ in these two cases. The decreased LOSP remained low for the duration of the recording in both cases. Figure 3 is a composite graph of all cases studied showing LOSP (mean \pm SEM) before and after sublingual ID $5 \mathrm{mg}$. Table 2 gives the individual data for each patient. In each case the lowest pressure recorded during the treatment is given.

The mean \pm SE LOSP before ID was $46 \cdot 3 \pm 2 \cdot 6$ $\mathrm{mmHg}$ and after ID $15.3 \pm 1.8 \mathrm{mmHg}$ (a fall of $65.9 \%$ ). The difference is statistically significant $(P<0.01)$. While ID reduced basal LOS pressure, it did not affect LOS relaxation during swallowing in 


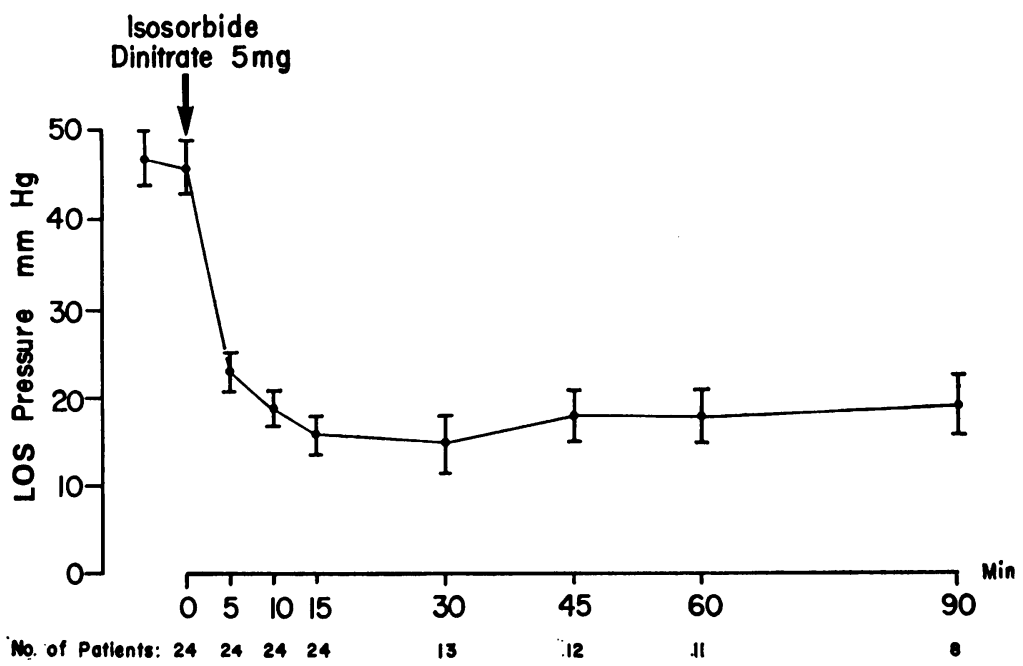

Fig. 3 A composite graph of the 24 cases studied. LOS pressure (mean $\pm S E M$ ) is shown before and at intervals after $5 \mathrm{mg}$ sublingual ID. The number of patients studied at each time interval is shown at the bottom.
Table 2 Effect of $5 \mathrm{mg}$ isosorbide dinitrate on LOSP

\begin{tabular}{|c|c|c|c|c|}
\hline \multirow[t]{2}{*}{ Patients } & \multicolumn{2}{|c|}{$\operatorname{LOSP}(\mathrm{mmHg})$} & \multirow{2}{*}{$\begin{array}{l}\text { Decrease in } \\
\text { LOSP } \\
(\%)\end{array}$} & \multirow{2}{*}{$\begin{array}{l}\text { Duration of } \\
\text { recording } \\
\text { (min) }\end{array}$} \\
\hline & Initial & After ID & & \\
\hline $\begin{array}{l}1 \\
2 \\
3 \\
4 \\
5 \\
6 \\
7 \\
8 \\
9 \\
10 \\
11 \\
12 \\
13 \\
14 \\
15 \\
16 \\
17 \\
18 \\
19 \\
20 \\
21 \\
22 \\
23 \\
24 \\
\text { Mean } \pm S E\end{array}$ & $\begin{array}{l}65 \\
45 \\
51 \\
39 \\
41 \\
45 \\
36 \\
30 \\
38 \\
51 \\
38 \\
29 \\
50 \\
63 \\
36 \\
63 \\
75 \\
39 \\
70 \\
38 \\
55 \\
29 \\
44 \\
41 \\
46 \cdot 3 \pm 2 \cdot 7\end{array}$ & $\begin{aligned} 28 \\
13 \\
13 \\
5 \\
34 \\
22 \\
11 \\
15 \\
11 \\
21 \\
16 \\
20 \\
16 \\
18 \\
16 \\
21 \\
13 \\
0 \\
25 \\
5 \\
5 \\
5 \\
30 \\
5 \\
15 \cdot 3 \pm 1 \cdot 8 \\
P<0 \cdot 01\end{aligned}$ & $\begin{array}{l}59 \cdot 6 \\
71 \\
74 \cdot 5 \\
81 \cdot 1 \\
17 \\
51 \cdot 1 \\
69 \cdot 4 \\
50 \\
71 \\
58 \cdot 8 \\
57 \cdot 8 \\
31 \\
68 \\
71 \cdot 4 \\
55 \cdot 5 \\
66 \cdot 6 \\
82 \cdot 6 \\
100 \\
64 \cdot 2 \\
86 \cdot 8 \\
90 \cdot 9 \\
82 \cdot 7 \\
31 \cdot 8 \\
87 \cdot 8 \\
65 \cdot 9 \\
\end{array}$ & $\begin{array}{r}>90 \\
>90 \\
>90 \\
15 \\
>60 \\
15 \\
15 \\
30 \\
15 \\
15 \\
15 \\
15 \\
15 \\
15 \\
15 \\
15 \\
15 \\
30 \\
>60 \\
>60 \\
>60 \\
>60 \\
>60 \\
>60\end{array}$ \\
\hline
\end{tabular}

any of the cases. No effect on the contractions of the oesophageal body was noted during ID treatment.

\section{DURATION OF ACTION}

The duration of recording in each case is given in Table 2. The LOS pressure began to drop within two to eight minutes (mean $\pm \mathrm{SE}=4.7 \pm 0.3 \mathrm{~min}$ ) after sublingual ID. The effect was maximal after six to 30 minutes (mean $\pm \mathrm{SE}=15 \cdot 3 \pm 1 \cdot 4 \mathrm{~min}$ ). In cases 8 and 18 the LOS pressure began to rise again towards control values after 30 minutes. In all other cases the pressure remained low for the duration of the recording; this includes the 11 patients whose pressure was recorded for 60 minutes or more.

All patients were given a sandwich to eat after the manometric study; 19 could swallow it without any dysphagia. On repeated questioning of the patients during the follow-up period most of them reported that the clinical duration of action was about two to three hours after sublingual ID $5 \mathrm{mg}$. Two patients reported a short duration of relief of dysphagia. Those were the same two patients who showed a rise in LOSP within 30 minutes during the manometric study. They were then given $10 \mathrm{mg}$ ID orally one half-hour before meals with a longer clinical result.

\section{CLINICAL RESULTS}

In one patient (no. 14) adequate follow-up information was not available; she was, therefore, excluded from the clinical study. Four patients (nos. 5, 7, 11, 16) did not derive any significant relief of dysphagia during ID therapy. Two of them underwent successful pneumatic dilatation; two refused further therapy.

Significant clinical benefit was thus obtained in 19 out of 23 patients. In eight improvement was graded as moderate (occasional dysphagia) and in 11 as good (no dysphagia). The duration of follow-up is shown in Table 3. In two of the 19 patients (nos. 9, 13) the clinical improvement continued for only two and six months respectively, after which a successful pneumatic dilatation was performed. In the other 17 patients the improvement continued for the duration of the follow-up. Of the 19 patients responding to ID therapy, 14 had no previous therapy for achalasia, while five had relapsed after previous therapy (two pneumatic dilatation, one cardiomyotomy, two both). 
Table 3 Duration of follow-up in patients with satisfactory clinical response to isosorbide dinitrate

\begin{tabular}{ll}
\hline Duration (months) & Patients (no.) \\
\hline $2-4$ & 10 \\
$5-7$ & 3 \\
$8-10$ & 0 \\
$11-13$ & 4 \\
$14-16$ & 1 \\
$17-19$ & 19 \\
Total & 19 \\
\hline
\end{tabular}

Table 4 Initial LOSP and clinical response to isosorbide dinitrate

\begin{tabular}{lllll}
\hline Initial LOSP (mmHg) & \multicolumn{2}{l}{ Clinical response } & \multicolumn{2}{c}{ Total } \\
\cline { 2 - 4 } & None & Moderate & Good \\
\hline $29-30$ & - & 3 & - & 3 \\
$31-40$ & 2 & 2 & 3 & 7 \\
$41-50$ & 1 & 3 & 2 & 6 \\
$51-60$ & - & - & 3 & 3 \\
$61-70$ & 1 & - & 2 & 3 \\
$71-80$ & - & - & 1 & 1 \\
Total & 4 & 8 & 11 & 23 \\
\hline
\end{tabular}

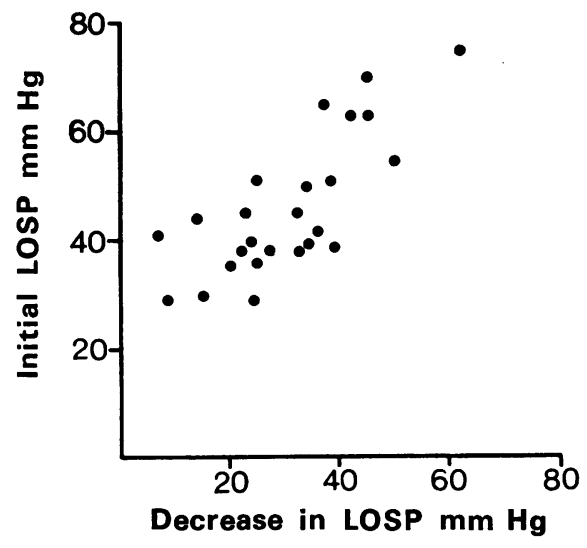

Fig. 4 Correlation between the initial LOS pressure (vertical axis and the decrease in pressure after ID (horizontal axis). $(\mathbf{R}=0.78 \pm 0.09)$.

Table 5 Decrease in LOSP $(\mathrm{mmHg})$ and clinical response to isosorbide dinitrate

\begin{tabular}{lllll}
\hline Decrease in LOSP & \multicolumn{3}{l}{ Clinical response } & \multirow{2}{*}{ Total } \\
\cline { 2 - 4 } & None & Moderate & Good \\
\hline $1-10$ & 1 & 1 & - & 2 \\
$11-20$ & - & 1 & 2 & 3 \\
$21-30$ & 2 & 3 & 1 & 6 \\
$31-40$ & - & 3 & 5 & 8 \\
$41-50$ & 1 & - & 2 & 3 \\
$51-60$ & - & - & 1 & 1 \\
$61-70$ & 4 & 8 & 11 & 23 \\
Total & & & & \\
\hline
\end{tabular}

Table 6 LOSP response to nitroglycerin $(0.65 \mathrm{mg})$

\begin{tabular}{lllll}
\hline Patients & \multicolumn{2}{l}{ LOSP $(\mathrm{mmHg})$} & $\begin{array}{l}\text { Onset of } \\
\text { action } \\
\text { (min) }\end{array}$ & $\begin{array}{l}\text { Duration of } \\
\text { effect } \\
\text { (min) }\end{array}$ \\
\cline { 2 - 5 } Initial & $\begin{array}{l}\text { After } \\
\text { nitroglycerin }\end{array}$ & & \\
\hline 1 & 41.2 & 10 & 7 & 3 \\
2 & 38.7 & 8.7 & 3 & 8 \\
3 & 58.7 & 16.2 & 1.5 & 2.5 \\
4 & 75.0 & 12.5 & 4 & 9 \\
5 & 62.5 & 17.5 & 4 & 8 \\
Mean \pm SE & $55.2 \pm 6.8$ & $13.0 \pm 1.7$ & $3.9 \pm 0.8$ & $6 \cdot 1 \pm 1.4$ \\
\hline
\end{tabular}

SIDE-EFFECTS

Seven patients complained of severe headache during sublingual ID treatment. Two of them were among the four without clinical relief; in the other five, the treatment was changed to $10 \mathrm{mg}$ ID orally with a satisfactory result and with relief of the headache. Another patient developed syncope and was then treated with the oral preparation with good results.

One young girl (no. 17) refused to take tablets continuously for social reasons and pneumatic dilatation was performed despite the good result of ID therapy for two months.

\section{CORRELATIONS}

The clinical response during ID therapy was correlated with several disease parameters. No definite correlation was found with duration of symptoms or oesophageal dilatation. There was a suggestion of a better clinical result in cases with higher LOS pressure (Table 4). There was also a suggestion of a correlation between a high initial LOSP and the drop in pressure after ID (Fig. 4). The correlation did not reach a level of statistical significance $(r=0.78 \pm$ 0.09).

In Table 5 the clinical result is correlated with the drop in LOS pressure. A higher drop in LOS pressure may be associated with a better clinical result. The data in both Tables 4 and 5 are not suitable for statistical analysis because of the small numbers involved.

\section{NITROGLYCERIN}

In five patients with achalasia the effect of a shortacting nitrate (nitroglycerin 0.65 sublingually) was evaluated in a separate study. The results given in Table 6 show a significant and rapid drop in LOSP which was, however, of short duration.

\section{Discussion}

Several drugs have been used in an attempt to overcome the functional obstruction of the LOS in achalasia. Anticholinergics ${ }^{2-7}$ and adrenergic 
blockers ${ }^{1}$ act on the nervous elements in the oesophageal wall. Results obtained with anticholinergics were variable and the use of adrenergic blockers is fraught with side-effects. Both are not commonly used in the treatment of achalasia.

Nitrites and nitrates are known to relax human smooth muscle of several systems, including the digestive tract and, in particular, the oesophagus..$^{13-16}$ Short-acting nitrates and nitrites were evaluated in achalasia in the 1940s and 1950s by four groups of investigators. ${ }^{8-11}$ All four were radiographic and clinical studies without manometric confirmation. These radiographic studies demonstrated a relaxation of the cardia with passage of the barium column into the stomach after amyl or octyl nitrite inhalation or sublingual nitroglycerin. The duration of action, as determined clinically or by radiographs was short, four to 30 minutes, and was associated with sideeffects such as headaches and hypotension. We are not aware of additional studies and nitrates are not currently used in the treatment of achalasia.

We first measured manometrically the effect of short-acting nitrates on the LOS pressure in achalasia (Table 6) and having objectively demonstrated a decrease in pressure proceeded to evaluate a longer acting compound to obtain a prolonged clinical effect and minimise side-effects. We believe that other smooth muscle relaxants should also be evaluated in the treatment of this disease.

The results obtained with isosorbide dinitrate $5 \mathrm{mg}$ sublingually are manometrically and clinically significant. The mean fall in LOS pressure was $66 \%$, similar to the approximately $70 \%$ after pneumatic dilatation. ${ }^{17}$ The duration of the measured fall in LOS pressure (30 to more than 90 minutes) and the clinical relief of dysphagia (up to two to three hours) after a single tablet are adequate for the ingestion of a regular meal. The duration of the clinical effect reported by our patients corresponds to the duration of the cardiovascular effect of ID as established by haemodynamic studies. ${ }^{18}$ One problem encountered with this treatment is the known loss of potency of nitrates with increasing shelf life. ${ }^{15}$ This may affect both the magnitude and duration of the clinical and manometric effect.

The proportion of satisfactory results $(19 / 23)$ does not differ markedly from that reported with pneumatic dilation or cardiomyotomy. ${ }^{19} 20$ Unlike the two other methods of treatment, no mortality or morbidity is involved. Side-effects were noted in a considerable proportion of patients $(8 / 24)$. This is more than usually encountered by cardiologists. The side-effects themselves were not serious, mostly headaches, and could, in some cases, be alleviated by substituting oral ID or another oral nitrate.

We cannot yet evaluate the duration of the bene- ficial effect of ID or the proportion of clinical failure with time. The duration of follow-up (up to 19 months) is still too short for this purpose. It should be noted that recurrences also occur after pneumatic dilatation $^{19-21}$ and even cardiomyotomy ${ }^{20-23}$ There were eight such patients in our series, and in five of these ID therapy was helpful.

To the best of our knowledge, this is the first report of its kind. The results have to be confirmed by other investigators, and more data have to be gathered before the eventual place of nitrates in the overall treatment of achalasia can be established.

\section{References}

${ }^{1}$ Nickerson M, Call LS. Treatment of cardiospasm with adrenergic blockade. Am J Med 1957; 11 : 123-7.

${ }^{2}$ Wright JT. Buscopan and esophageal achalasia. $J$ Radiol 1961; 34: 113-9.

${ }^{3}$ Redo SF, Bauer ChM. Management of achalasia in infancy and childhood. Surgery 1963; 53: 263-6.

${ }^{4}$ Yon J, Christensen J. An uncontrolled comparison of treatment for achalasia. Ann Surg 1975; 182: 672-6.

${ }^{5}$ Castel DO. Achalasia and diffuse esophageal spasm. Arch Intern Med 1976; 136: 571-9.

${ }^{6}$ Lobis JB, Fischer RS. Anticholinergic therapy for achalasia. A controlled study. Gastroenterology 1976; 70: 976.

${ }^{7}$ Christensen J. Effects of drugs on esophageal mobility. Arch Intern Med 1976; 136: 532-7.

${ }^{8}$ Ritvo M, McDonald EJ. Value of nitrates in cardiospasm (achalasia of esophagus): preliminary report. AJR 1940; 43: 500-8.

${ }^{9}$ Douthwaite AJ. Achalasia of cardia. Treatment with nitrites. Lancet 1943; 2 : 353-4.

${ }^{10}$ Field CE. Octyl nitrite in achalasia of the cardia. Lancet 1944; 2 : 848-51.

${ }^{11}$ Lozber SM, Shay H. Roentgen studies of esophageal transport in patients with dysphagia due to abnormal motor function. Gastroenterology 1955; 28: 697-714.

${ }^{12}$ Pope CE. A dynamic test of sphincter strength. Its application to the lower esophageal sphincter. Gastroenterology 1967; 52: 779-86.

${ }^{13}$ Stein GN. Roentgenologic diagnosis. In: Bockus HL, ed. Gastroenterology. Philadelphia: Saunders, 1966: I: 164.

${ }^{14}$ Orlando RC, Bozymski EM. Clinical and manometric effects of nitroglycerin in diffuse esophageal spasm. $N$ Engl J Med 1973; 289: 23-5.

${ }^{15}$ Nickerson M. Vasodilator drugs. In: Goodman LS, Gilman A, eds. The pharmacological basis of therapeutics. New York: Macmillan, 1975: 733.

${ }^{16}$ Goyal RR, Rattan S. Neurohumoral, hormonal and drug receptors for the lower esophageal sphincter. Gastroenterology 1978; 74: 598-619.

${ }^{17}$ Cohen S, Lipshutz W. Lower esophageal sphincter dysfunction in achalasia. Gastroenterology 1971; 61: 814-20.

${ }^{18}$ Warren SE, Francis GS. Nitroglycerin and nitrate esters. Am J Med 1978; 65: 53-62. 
${ }^{19}$ Vantrappen G, Hellemens J, Deloof W, Valembous P, Vandenbroucke Y. Treatment of achalasia with pneumatic dilation. Gut 1971; 12: 268-75.

${ }^{20}$ Arvanitakis C. Achalasia of the esophagus. A reappraisal of esophagomyotomy vs forceful pneumatic dilation. Dig Dis 1975; 20: 841-6.

${ }^{21}$ Vantrappen G, Van Goidsenhoven GE, Verbeke S, Vander Berghe $G$, Vandenbroucke $Y$. Manometric studies in achalasia of the cardia, before and after pneumatic dilation. Gastroenterology 1963: 45: 317-25. ${ }^{22}$ Rees JR, Thorbjarnarson B, Barnes WM. Achalasia: results of operation in 84 patients. Ann Surg 1970; 171: 195-201.

${ }^{23}$ Black J, Vorbach AN, Collis JL. Results of Heller's operation for achalasia of the esophagus. The importance of hiatal repair. Br J Surg 1976; 63: 949-53. 